\title{
Strategic noise mapping of the agglomeration of Bologna, Italy
}

\author{
M. Garai \& D. Fattori \\ Department of Energy, \\ Nuclear and Environmental Control Engineering (DIENCA), \\ University of Bologna, Italy
}

\begin{abstract}
Transportation noise makes the largest contribution to environmental noise. The European Directive 2002/49/EC relating to the assessment and management of environmental noise requires EU Member States to assess and reduce environmental noise by means of noise mapping and subsequent action plans (to manage noise issues and effects) for roads, railways, airports and urban agglomerations. The agglomeration of Bologna, Italy, consists of the municipality of Bologna and four other smaller municipalities, overall accounting for more than 450000 inhabitants. It includes some major highways, railways and a national airport. The regional Authority, Regione EmiliaRomagna, assigned the task to fulfil the END to DIENCA. This paper describes the organization and methods implemented to make the strategic noise mapping of the agglomeration of Bologna, reporting on the man problems encountered, e.g. the harmonization of data coming from different sources, the selection of a digital ground model suited for the subsequent acoustic simulation, etc., and the ways to solve them. The overall noise maps of the agglomeration of Bologna are presented. Some remarks about the accuracy of predictions and the main sources of uncertainty are also presented.
\end{abstract}

Keywords: environmental noise, European directive 2002/49/EC, noise mapping, Bologna agglomeration, action plans.

\section{Introduction}

Noise in the environment is one of the main environmental problems in Europe, and transportation noise makes the largest contribution to environmental noise. 
The European Directive 2002/49/EC relating to the assessment and management of environmental noise (END) [1] requires EU Member States to assess and reduce environmental noise by means of noise mapping and subsequent action plans (to manage noise issues and effects, including noise reduction if necessary) for roads, railways, airports and urban agglomerations. "Agglomeration" means part of the territory having a population in excess of 100000 persons and a population density such that the Member State considers it to be an urbanised area.

The agglomeration of Bologna, Italy, consists of the municipality of Bologna and four other smaller municipalities (Casalecchio di Reno, Calderara di Reno, Castel Maggiore and San Lazzaro di Savena), overall accounting for more than 450000 inhabitants. It includes some major highways, railways and a national airport. The regional Authority, Regione Emilia-Romagna, was assigned the task to fulfil the END to DIENCA.

The END [1] indicates that noise levels can be determined by computation or measurement methods, but the measurement of the yearly average noise levels at all the assessment positions required is likely to require an impractically large number of long-term noise measurements. Furthermore, when predicting the effects of proposed actions on noise levels, only computation methods are applicable. Thus the strategic noise mapping of Bologna was carried out by computer simulation. Input data were provided by Regione Emilia-Romagna and the City of Bologna. When some data were lacking, either in coverage or in detail, the toolkits of the "good practice guide" (GPG) issued by the European Commission working group on the assessment of exposure to noise (WG-AEN) were applied [2]. They provide guidance on possible steps to be taken and an indication of the corresponding accuracy of results.

\section{Noise level indicators}

According to the END, art. 5, Member States must apply the noise indicators $L_{\text {den }}$ (for overall noise annoyance) and $L_{\text {night }}$ (for sleep disturbance) for the preparation of strategic noise mapping. The day-evening-night level $L_{\mathrm{den}}$ in A-weighted decibels $(\mathrm{dB})$ is defined by the following formula:

$$
L_{d e n}=10 \lg \frac{1}{24}\left(14 \cdot 10^{\frac{L_{d a y}}{10}}+2 \cdot 10^{\frac{L_{\text {evening }}+5}{10}}+8 \cdot 10^{\frac{L_{n i g h t}+10}{10}}\right)
$$

in which:

$L_{\text {day }}$ is the A-weighted long-term average sound level as defined in ISO 19962:1987 [3], determined over all the day periods of a year (06-20 in Italy),

$L_{\text {evening }}$ is the A-weighted long-term average sound level as defined in ISO 19962:1987 [3], determined over all the evening periods of a year (20-22 in Italy),

$L_{\text {night }}$ is the A-weighted long-term average sound level as defined in ISO 1996-

2:1987 [3], determined over all the night periods of a year (22-06 in Italy). 
The noise indicators $L_{\text {den }}$ and $L_{\text {night }}$ must be computed at the height of $4 \mathrm{~m}$ above the ground using the "recommended interim methods" [1, 4]:

- for road traffic noise: the French national computation method "NMPBRoutes-96", referred to in the French standard AFNOR XPS 31-133;

- for railway noise: the Netherlands national computation method "Rekenen Meetvoorschrift Railverkeerslawaai '96" (RMR);

- $\quad$ for aircraft noise: the method described in ECAC-CEAC Doc. 29 [5];

- $\quad$ for industrial noise: the method described in ISO 9613-2.

\section{Digital ground model}

The first step in constructing a large scale noise model is the creation of a 3D digital ground model. For the city of Bologna a very detailed GIS covering is available (CTC, 1:2 000), but it doesn't include the smaller municipalities, represented only on a regional scale covering (CTR, 1:5 000): see figure 1. So, it was necessary to check the consistency of the two representations and to merge them in one, using the WGS84 reference system in the UTM (Universal Transverse Mercator) projection. The acoustic characteristic of the ground have been linked to land usage, as reported in the CORINE land cover database available on the Internet, and expressed by ground factor values (table 1).
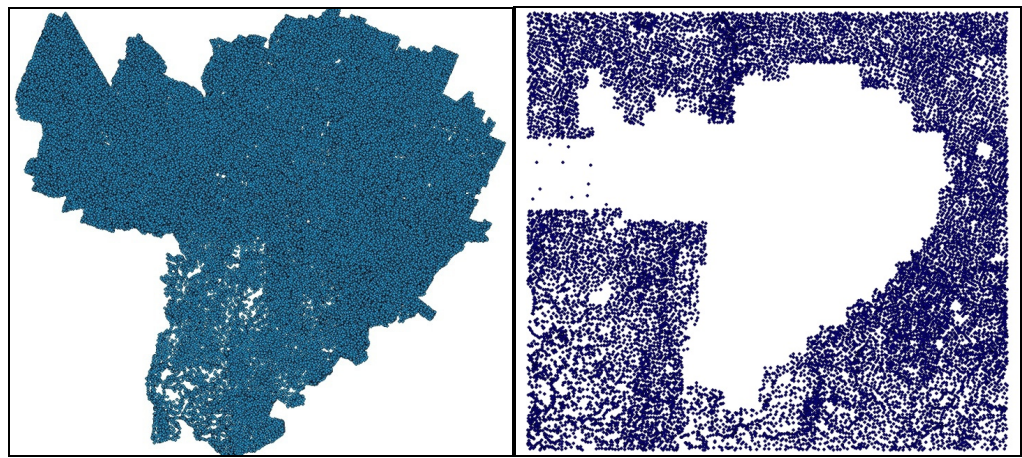

Figure 1: Overview of the GIS coverings for the DGM. Left: CTC, 1:2000 scale. Right: CTR, 1:5000 scale.

Table 1: $\quad$ Example values of the ground factor $G$.

\begin{tabular}{|c|c|}
\hline Land use & Ground factor $\boldsymbol{G}$ \\
\hline Residential areas: dense - sparse & $0-0,3$ \\
\hline Industrial and commercial areas & 0 \\
\hline Roads, railways, etc. & 0 \\
\hline Airports & 0,5 \\
\hline Parks inside city & 0,5 \\
\hline Agricultural areas & $0,5-1$ \\
\hline
\end{tabular}




\section{Buildings and population}

One of the main tasks of the computation is the estimation of the number of people in the agglomeration that are exposed to specific noise levels. For this it is necessary to insert in the model all the buildings of the agglomeration with the estimated number of people living in them.

Buildings were available on a geo-referenced file, and the estimated number of people living in each small portion of the agglomeration was available on another file coming from statistical surveys (figure 2). GIS tools can link the two

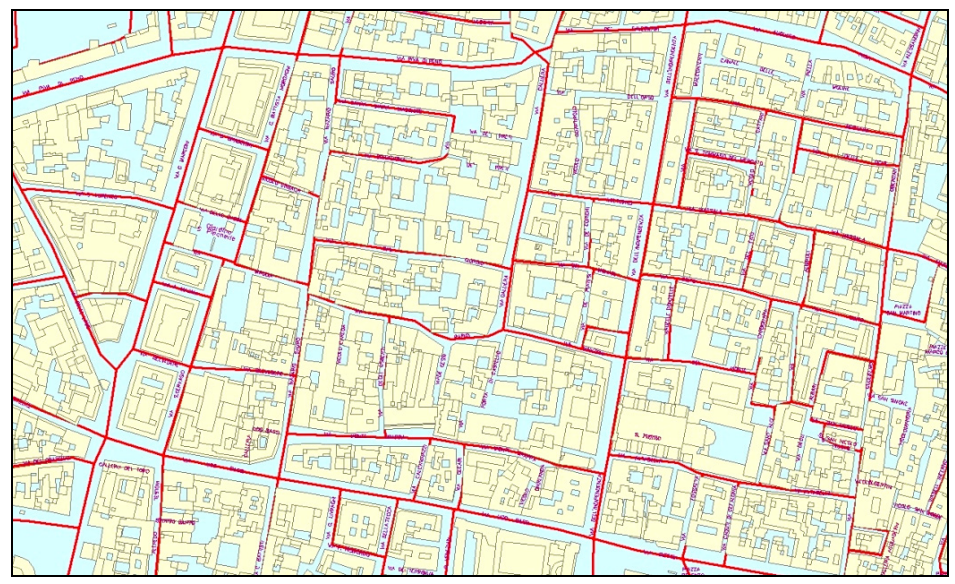

Figure 2: Example of the subdivision of the urban area used for the statistical survey of population.

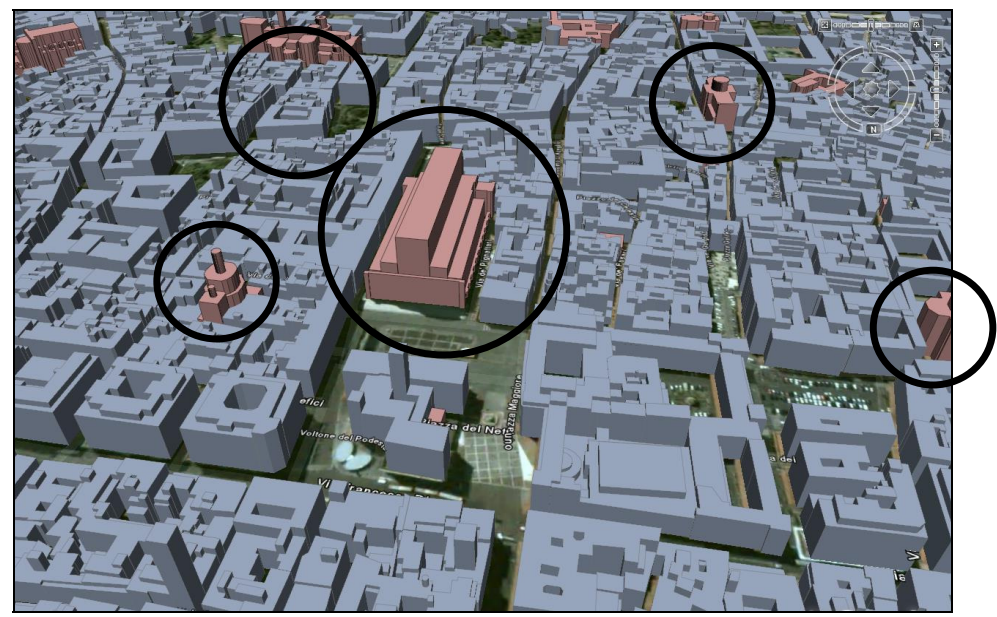

Figure 3: Example of non-residential buildings, circled in black, in the acoustic model. 
data sets and distribute the population in residential buildings, but before it was necessary to check the effective use of buildings, in order to avoid having nonresidential buildings (administrative buildings, churches, commercial areas, etc.) considered as residential and thus including exposed population (figure 3 ). This operation had to be done manually, taking advantage from the aerial pictures services available on the Internet.

\section{Noise sources}

\subsection{Road traffic}

For urban traffic, the vehicle numbers have been extracted from the city traffic model, which is a simplified version of the real situation, but consistent with it; this is not of concern in a large scale acoustic model like the present one (figure 4). Bologna is a key node of the Italian highway network, with main highways surrounding half of the most urbanized area from East to West (figure 4) and having very trafficked freeways on both sides; see tables 2 and 3. Overall, this is the most relevant noise source of the agglomeration.

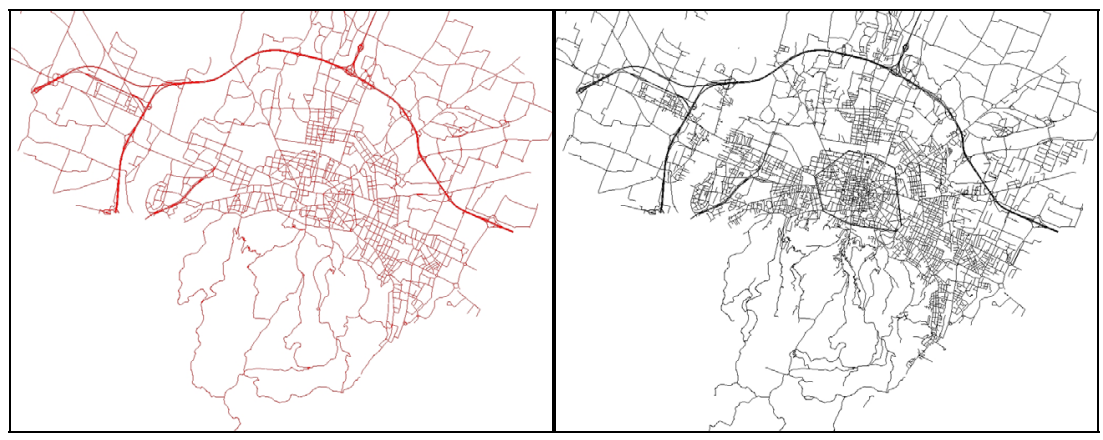

Figure 4: Bologna road network. Left: traffic model. Right: real situation.

\subsection{Railways}

Bologna hosts one of the most important passenger station in Italy, located near the city centre and has a dedicated goods station, located in the Eastern outskirts. They are connected to many rail lines. According to the END [1], in the present model all lines having at least 60000 train passages per year have been included. The passenger station has been modelled as a set of low speed lines $(40 \mathrm{~km} / \mathrm{h})$. The goods station (figure 5) have been modelled as an "area source", with noise emissions calibrated on accurate noise measurements, because noise emissions are caused by separating and joining freight cars at low speed and braking them; this cannot be modelled using the customary noise models for running trains. 
Table 2: $\quad$ Average traffic flows and speeds on the highways around Bologna.

\begin{tabular}{|c|c|c|c|c|}
\hline Time slice & $\begin{array}{c}\text { Light v. } \\
\text { num./h }\end{array}$ & $\begin{array}{c}\text { Light v. } \\
\text { speed } \mathbf{~ k m / h}\end{array}$ & $\begin{array}{c}\text { Heavy v. } \\
\text { num./h }\end{array}$ & $\begin{array}{c}\text { Heavy v. } \\
\text { speed } \mathbf{~ k m} / \mathbf{h}\end{array}$ \\
\hline Day (06-20) & 1570 & 110 & 554 & 90 \\
\hline $\begin{array}{c}\text { Evening } \\
(20-22)\end{array}$ & 1100 & 110 & 389 & 90 \\
\hline $\begin{array}{c}\text { Night } \\
(22-06)\end{array}$ & 237 & 110 & 277 & 90 \\
\hline
\end{tabular}

Table 3: $\quad$ Average traffic flows and speeds on the freeway around Bologna.

\begin{tabular}{|c|c|c|c|c|}
\hline Time slice & $\begin{array}{c}\text { Light v. } \\
\text { num./h }\end{array}$ & $\begin{array}{c}\text { Light v. } \\
\text { speed } \mathbf{~ k m / h}\end{array}$ & $\begin{array}{c}\text { Heavy v. } \\
\text { num./h }\end{array}$ & $\begin{array}{c}\text { Heavy v. } \\
\text { speed } \mathbf{~ k m} / \mathbf{h}\end{array}$ \\
\hline Day (06-20) & 2539 & 70 & 251 & 70 \\
\hline $\begin{array}{c}\text { Evening } \\
(20-22)\end{array}$ & 1523 & 70 & 151 & 70 \\
\hline $\begin{array}{c}\text { Night } \\
(22-06)\end{array}$ & 564 & 70 & 125 & 70 \\
\hline
\end{tabular}

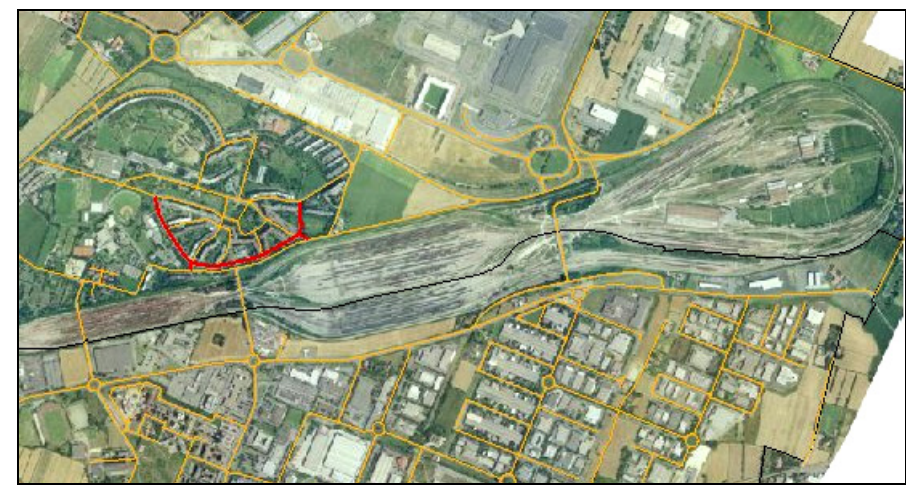

Figure 5: Aerial view of the goods station "Scalo merci San Donato".

\subsection{Airport}

Bologna national airport "Guglielmo Marconi” has a runway directed 12-30 with dimensions 2800x45 m and two lateral shoulders. Only one of the allowed air tracks passes over the centre of Bologna and is used only in exceptional events. In 2006 the airport hosted more than 4000000 passengers and had about 63600 movements (take off or landing). The most common aircrafts are MD80 and Boeing 737.

At "Guglielmo Marconi" airport, noise impact is routinely computed using INM [6], the computer code which is a standard de facto and can be used in accordance with ECAC-CEAC Doc. 29 [5]. This model already includes all details about tracks, aircraft type, engines, take off and landing procedures, etc. 
So it was decided to keep the noise maps of airport noise created with INM, and then merge them with the maps of the global model of Bologna, which includes all other noise sources. Figures 6 and 7 shows the airport noise maps superimposed to the agglomeration of Bologna.

\section{Implementation issues}

All the data have been merged in one acoustic model implemented using the SoundPLAN commercial software [7] on a HP Workstation networked with five supporting computers. The general parameters have been set on the safe side in order to not compromise the accuracy (table 4).

Table 4: $\quad$ General data about the computer model.

\begin{tabular}{|c|c|}
\hline Description & Value \\
\hline N. of buildings & 70209 \\
\hline N. of road arcs & 9570 \\
\hline N. of railway arcs & 58 \\
\hline N. of reflections considered & 2 \\
\hline Maximal search radius & $1000 \mathrm{~m}$ \\
\hline Tolerance & $0,30 \mathrm{~dB}$ \\
\hline
\end{tabular}

Table 5: $\quad$ Measured and calculated values.

\begin{tabular}{|c|c|c|c|c|}
\hline Location & $\begin{array}{c}\text { Measured } \\
\boldsymbol{L}_{\mathbf{d e n}}, \mathbf{d B}\end{array}$ & $\begin{array}{c}\text { Measured } \\
\boldsymbol{L}_{\text {night }}, \mathbf{d B}\end{array}$ & $\begin{array}{c}\text { Computed } \\
\boldsymbol{L}_{\mathbf{d e n}}, \mathbf{d B}\end{array}$ & $\begin{array}{c}\text { Computed } \\
\boldsymbol{L}_{\text {night }}, \mathbf{d B}\end{array}$ \\
\hline $\begin{array}{c}\text { Via Emilia } \\
\text { Ponente }\end{array}$ & 76,8 & 69,9 & 77,1 & 69,4 \\
\hline $\begin{array}{c}\text { Viale } \\
\text { Ercolani }\end{array}$ & 73,8 & 66,4 & 74,8 & 66,3 \\
\hline $\begin{array}{c}\text { Via San } \\
\text { Vitale }\end{array}$ & 76,0 & 68,5 & 76,7 & 68,3 \\
\hline $\begin{array}{c}\text { Railway } \\
\text { line BO-MI }\end{array}$ & 79,1 & 72,2 & 79,4 & 72,8 \\
\hline
\end{tabular}

Before launching the final calculation, several trials have been done, calibrating the model versus the results of measurements in carefully selected points. Table 5 shows the comparison at some exemplary locations. A detailed analysis has shown that GIS imported data are accurate enough in geometry, while some adjustments are needed in the number of assumed vehicle passages in order to match the real situation.

\section{Strategic noise maps}

The final results have been obtained both as noise indicator maps and tables reporting the number of people affected in a certain area and the number of dwellings exposed to certain values of a noise indicator in a certain area. 


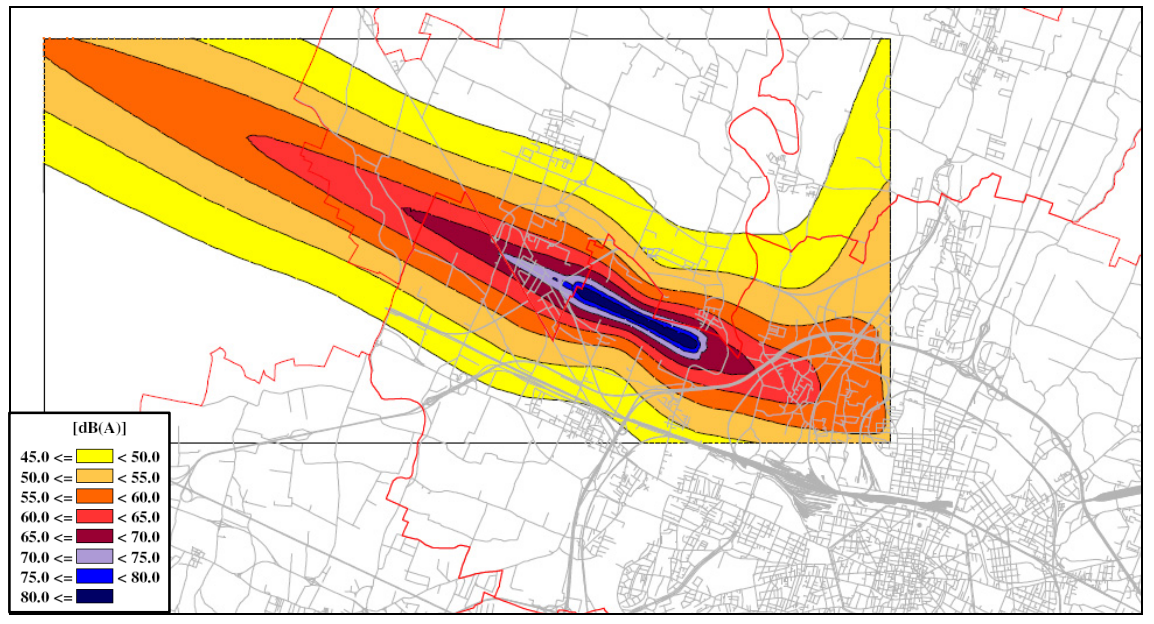

Figure 6: Bologna airport noise map: $L_{\mathrm{den}}$ in $\mathrm{dB}$.

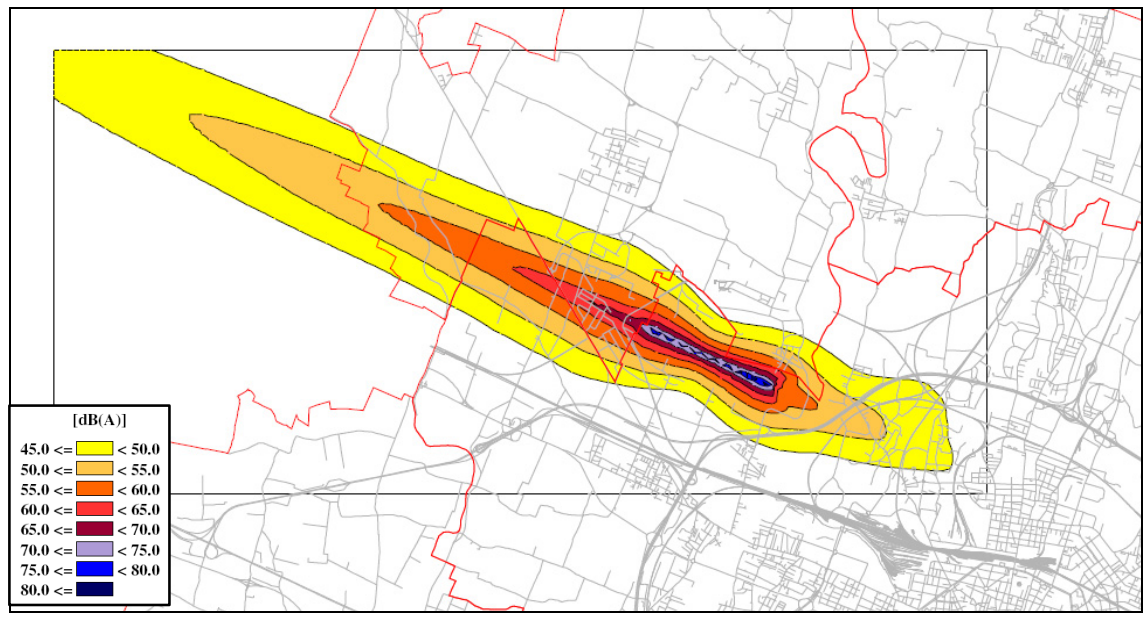

Figure 7: $\quad$ Bologna airport noise map: $L_{\text {night }}$ in $\mathrm{dB}$.

Figure 8 shows the strategic noise map for the 24-hours period $\left(L_{\mathrm{den}}\right)$. Figure 9 shows the strategic noise map for night time $\left(L_{\text {night }}\right)$. In both cases buildings have been removed from the map for the sake of clarity.

\section{Conclusions and future work}

The strategic noise maps of Bologna have been produced in compliance with the Directive 2002/49/EC [1]. For this work a computer model have been built, including 3D representations of ground, buildings, roads, railways, airport, etc. The maps show that the major source of noise annoyance is road traffic; overall 


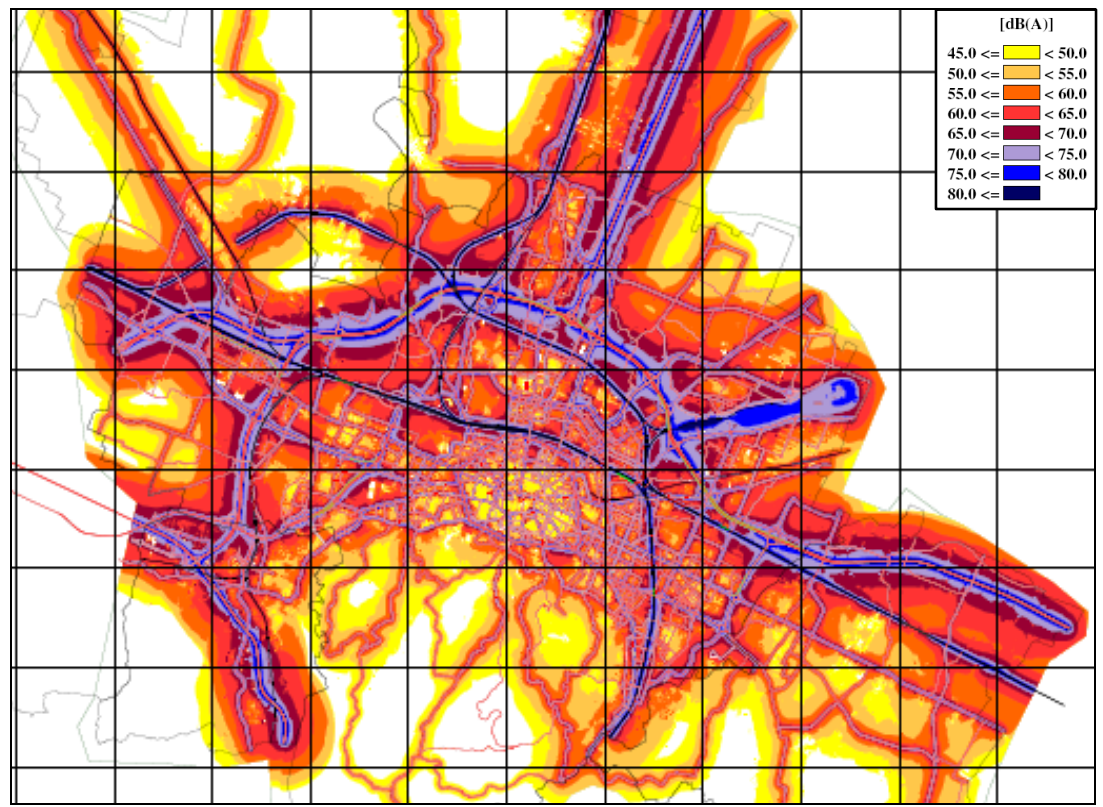

Figure 8: $\quad$ Strategic noise map: $L_{\mathrm{den}}$ in $\mathrm{dB}$. Airport not included.

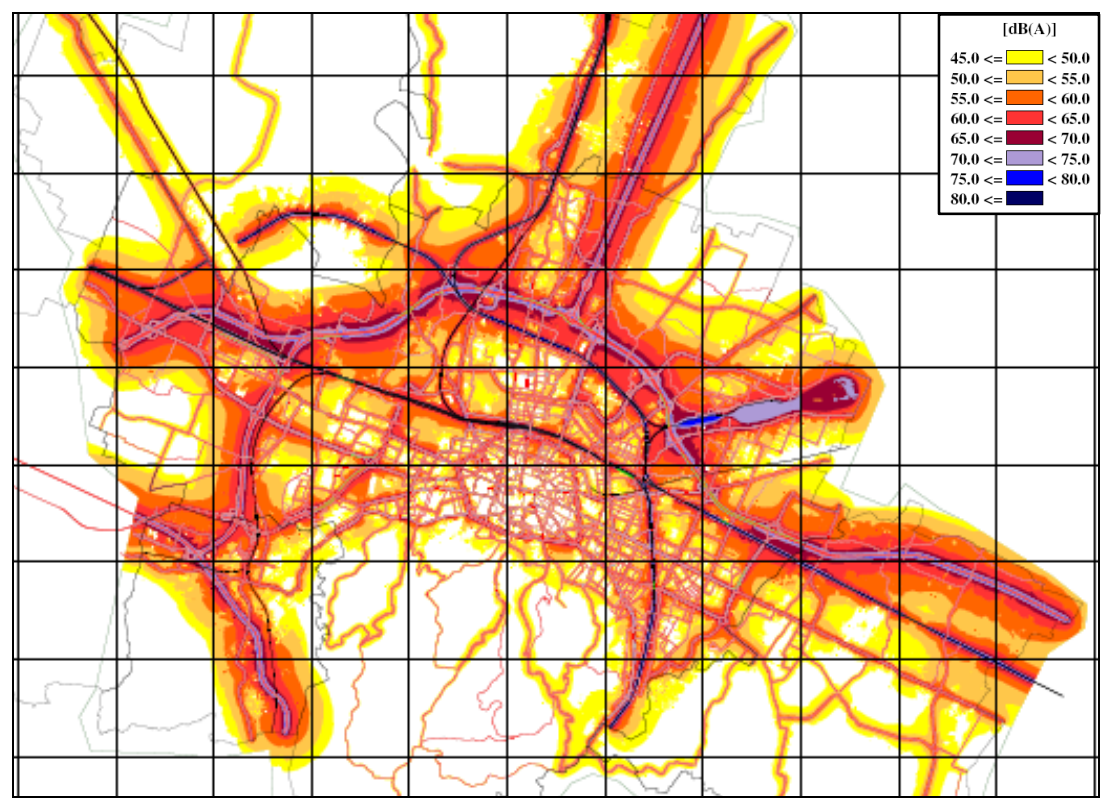

Figure 9: $\quad$ Strategic noise map: $L_{\text {night }}$ in $\mathrm{dB}$. Airport not included. 
the greatest noise emissions come from the highway/freeway system and the main concentration of exposed people is found around the city centre and aside major roads. The accuracy of predictions is influenced by the quality of input data, the availability of measured noise levels for model calibration and by the simplification strategies used to speed up the calculation.

Now the city of Bologna can afford the action plan with a powerful tool for evaluating different noise reduction solutions in terms of predicted noise reduction and, more important, predicted reduction of affected people. In order to accomplish this task, it is necessary to tune the large-scale noise model to get the desired accuracy at a smaller scale. Therefore, an extended comparison of calculated maps with local measurements is required. This could be done realising a network of noise monitoring terminals over the territory of the agglomeration.

\section{References}

[1] Directive 2002/49/EC of the European Parliament and of the Council, Relating to the assessment and management of environmental noise, Official Journal of the European Communities, L189/12-25, 18 July 2002.

[2] European Commission Working Group - Assessment of Exposure to Noise (WG-AEN), Good practice guide for strategic noise mapping and the production of associated data on noise exposure, Vr. 2, 13 August 2007.

[3] ISO 1996-2:1987, Acoustics - Description and measurement of environmental noise. Part 2: Acquisition of data pertinent to land use, ISO: Geneva, 1987.

[4] European Commission Recommendation of 6 August 2003, Concerning the guidelines on the revised interim computation methods for industrial noise, aircraft noise, road traffic noise and railway noise, and related emission data, Official Journal of the European Communities, L212/49-64, 22 August 2003.

[5] ECAC-CEAC, Doc. 29 - Report on standard method of computing noise contours around civil airports, 1997.

[6] Integrated Noise Model (INM) Version 7.0 User's Guide, FAA: Washington DC, 2008.

[7] SoundPLAN user's manual - Version 6.4, Braunstein + Berndt $\mathrm{GmbH} /$ SoundPLAN LLC: Backnang, 2007. 